\title{
$\checkmark$ Research Square \\ Effects of polishing vs. glazing on dental ceramic wear: A comparative in vitro study
}

Mohammed Abujalala ( $\nabla$ dr.moh.jalala@hotmail.com )

Near East University https://orcid.org/0000-0003-1509-5711

\section{A.Nehir Özden}

Near East University

\section{Research article}

Keywords: wear; monolithic zirconia; lithium disilicate; polymer infiltrated ceramic

Posted Date: October 9th, 2019

DOI: https://doi.org/10.21203/rs.2.15751/v1

License: (9) This work is licensed under a Creative Commons Attribution 4.0 International License. Read Full License 


\section{Abstract}

Background: This study analyzed the wear behavior caused by steatite antagonists to four dental ceramic materials, comparing this between two surface treatments: polishing and glazing.

Methods: Thirty flat samples $(10 \times 8 \times 2 \mathrm{~mm})$ were prepared from each of four ceramics: IPS e.max CAD (IPS), GC Initial LiSi Press (LP), Vita Enamic (VE), and monolithic zirconia (MZ). Subgroups of samples were finished by polishing or glazing or neither (as controls). The samples were subjected to computercontrolled chewing simulation $\left(240,000\right.$ cycles of $49 \mathrm{~N}$ at $1.6 \mathrm{~Hz}$, with thermocycling at $\left.5 / 55^{\circ} \mathrm{C}\right)$, with steatite balls as antagonists. The samples and antagonists were visualized before and after the test with a laser abrasion measurement system, a CAD/CAM scanner, and electron microscopy scanning, and the volumes lost from the tested samples and antagonists were analyzed.

Results: For the MZ samples, the polished samples showed significantly less volume loss than the glazed samples $(0.0200 \mathrm{~mm} 3$ vs. $0.0305 \mathrm{~mm} 3 ; p=0.0001)$, whereas there was significantly greater antagonist volume loss $(0.0365 \mathrm{~mm} 3$ vs. $0.0240 \mathrm{~mm} 3 ; p=0.011)$. There were no significant differences between the subgroups for IPS, VE, and LP, although antagonist volume losses were non-significantly greater with the glazed samples than with the polished samples.

Conclusions: Polishing MZ had adverse effects on the corresponding antagonist wear. Glazed MZ showed the lowest antagonist wear.

\section{Background}

One of the most important goals in dentistry is to develop restorative materials that have ideal properties for restoring function and aesthetics [1]. Such materials should meet appropriate mechanical resistance and optical requirements without compromising on aesthetic quality, which is an important consideration alongside functionality and health of the oral environment [2].

As with enamel, dentin, and other materials, restorative materials are subjected to wear. The nature of the wear depends on the type of material, the forces applied, whether there is sliding movement, the $\mathrm{pH}$ of the saliva, the abrasive nature of food, parafunctional habits, and the structure of the enamel [3-5]. Wear resistance is important for maintaining the durability of the restorative material and is the key to stable occlusion. Clinical tests have demonstrated that metal alloys and ceramic materials are usually highly resistant to wear, whereas composites and unfilled polymers can suffer material loss within a short time, depending on the material type [4].

Zirconia exhibits excellent properties, such as high flexural strength, superior fracture resistance, and color stability, so it is widely used as an aesthetic dental restorative material. However, data are limited about the high antagonist wear and loss of structure resulting from its abrasive properties. A common problem with veneered zircon restoration has been chipping or fracture of the veneering ceramics. To 
prevent such problems, zirconia with anatomical contours (monolithic zirconia) has been produced without ceramic veneering, allowing aesthetic enhancement and improved strength [6-8].

Ceramic materials have valuable characteristics such as high biocompatibility, hardness, and aesthetic characteristics, but the abrasiveness of these materials against the enamel and dental material of the antagonist remains a clinical issue [2]. Relatively soft ceramics have been reported to cause greater wear to the opposing enamel than that that of harder ceramics. As a result, various polymer materials have been introduced to overcome these shortcomings in addition to their aesthetic and functional properties [9].

Various processing methods are used for processing dental ceramic materials, such as conventional porcelain build-up, the press technique, and computer-aided design/computer-aided manufacturing (CAD/CAM) technology. Over the last decade, pressable glass-ceramic systems have gained popularity because of their ease of fabrication, excellent mechanical properties, and relative kindness to natural dentition $[9,10]$. The dimensional stability of pressed porcelain makes these ceramic materials excellent for restoration. Two currently available lithium disilicate glass-ceramic products are IPS e.max Press and IPS e.max CAD, and several companies are now introducing other lithium disilicate glass-ceramic products for use with the pressing method. However, data about the physical properties of these materials are limited, requiring further research [10].

Studies have reported that the final mechanical characteristics and long-term efficiency of glass-ceramics depend on intrinsic and extrinsic factors. The intrinsic factors include the crystal size, amount, shape, and homogeneity of the materials, as well as their and coefficient of thermal expansion or contraction. The extrinsic factors, including $\mathrm{pH}$ level differences, humidity, thermal shocks, chewing cycles, and maximum loads during mastication, are all critical for the success of the restoration [11].

There is now a new generation of restorative materials that deliver strength and color stabilization of the dental ceramics with lower abrasive efficiency of the composite. One such product is Vita Enamic (comprising $86 \mathrm{wt} \%$ feldspathic ceramic and $14 \mathrm{wt} \%$ polymer), which has a structure similar to that of a polymer-infiltrated ceramic network [12]. Strengthening a ceramic with a network of polymers that penetrate each other produces a material that exhibits the favorable properties of both the ceramic and the composite resin. The interpenetration of the polymer results in less antagonistic wear and cracking than with dental ceramics, and the flexural strength of this material can be considerably higher than that of a porous ceramic or a polymer alone [13].

Dental wear is a complex process that results in irregular loading on the occlusal surface, loss of the tooth surface substance, and changes in masticatory functions. Many factors influence the surface roughness and wear of the restorative materials and the antagonist tooth, including the quality of the finishing and the polishing or glazing of the occlusal surface of the dental ceramic [5]. Finishing and polishing techniques have been identified that create surfaces comparable to or better than those of glazed porcelain [14]. However, it has been reported that, although the surface glazing of ceramics reduced the wear on the opposing antagonists, the glazed layer was easily removed after a short period 
of functioning [15]. In addition, the wear behavior of polished zirconia showed only marginal wear on the antagonists and almost no wear in the material itself [15].

To further clarify the effects of different finishing procedures, the present study evaluated the wear behavior of dental ceramics and their abrasiveness on the antagonist after polishing or glazing, to establish which type of finish achieved the lowest material loss and antagonist wear.

\section{Methods}

\section{Ceramics tested and study protocol}

This in vitro study used a two-body wear test to evaluate wear for four dental ceramic materials subjected to three different surface treatments. The four ceramic materials were IPS e.max CAD (IPS), monolithic zirconia (MZ), GC Initial LiSi Press (LP), and VITA Enamic (VE); details of these materials, including the manufacturers, are listed in Table 1. For each material, 30 samples with dimensions $10 \times 8 \times 2 \mathrm{~mm}$ were prepared according to the manufacturers' instructions. Each set of samples was divided into three subgroups (each $n=10$ ) that were subjected to different surface treatments: polishing, glazing, or neither (as controls). Each sample was then subjected to a two-body wear test with a steatite antagonist and to thermocycling. The samples and antagonists were examined before and after the tests to measure any volume loss.

\section{Fabrication of the LP samples}

Using CAD/CAM design and a milling machine, 30 wax patterns for ceramic discs $(10 \times 8 \times 2 \mathrm{~mm})$ were fabricated from a CAD wax block (ProArt CAD Wax; Ivoclar Vivadent, Schaan, Liechtenstein) and sprued. The wax pattern was invested using investment material (LiSi Press Vest; GC Corporation, Tokyo, Japan) and placed in a rubber investment ring with the funnel facing down in a ceramic press furnace preheated to $850^{\circ} \mathrm{C}$. A cold LiSi Press ingot was then inserted into the investment ring, which was placed in the furnace and the selected press program started (Ivoclar Vivadent EP500, $898^{\circ} \mathrm{C}$ ). At the end of the program, the casts were devested by blasting with glass beads at a pressure of 4 bar. The sprues were cut off with a suitable disk and the areas around them smoothed.

\section{Fabrication of the MZ samples}

Thirty samples of the required dimensions were designed and fabricated from an MZ block (CopraSupreme $98 \times 14$ mm S Zr blank HT-S 1100 MPa; White peaks Dental Solutions, Hamminkeln, Germany) using the CAD/CAM milling machine. These were then sintered at $900{ }^{\circ} \mathrm{C}$.

\section{Fabrication of the IPS and VE samples}


CAD/CAM blocks of IPS and VE were cut into 30 samples of the required dimensions using a micro CAD cutting device (MICRACUT 201; Metkon Instruments Inc., Bursa, Turkey).

\section{Surface treatment}

All the sample surfaces were abraded with silicon carbide grinding paper (p240, p500, p1200, p2400, and p4000) under water cooling and then cleaned in an ultrasonic bath for $10 \mathrm{~min}$. The cut samples are shown in Fig. 1a. Ten samples of each material were then glazed and ten were polished, as described below. The remaining ten samples were left untreated as controls. For fixation during the two-body wear simulation, the samples were embedded at the center of the top of a cylinder (height, $30 \mathrm{~mm}$; diameter, 25 $\mathrm{mm}$ ) of cold acrylic resin (HinriPress; Goslar, Germany). The cylinders were color-coded according to the surface treatment (Fig. 1b).

\section{Glazing}

The MZ samples were glazed using InSync Spray Glaze (Jensen Dental, North Haven, CT, USA) in a sintering furnace (inFire HTC Speed Sinterofen; Sirona Dental Systems GmbH, Bensheim, Germany) at $790^{\circ} \mathrm{C}$, according to the manufacturer's instructions. The IPS samples were glazed with fluorescent paste (IPS e-max CAD Crystall Glaze Paste; Ivoclar Vivadent) and fired according to the manufacturer's instructions in a furnace (Programat EP 5000; Ivoclar Vivadent), using the IPS e.max crystallization and glazing program. The LP samples were glazed using glazing paste (GC Initial Lustre Pastes NF; GC Corporation). The VE samples were glazed using a special polymerizing curing light (VALO Cordless; Ultradent Products, Inc., South Jordan, UT, USA) with a stain and glaze kit (VITA ENAMIC Glaze; VitaZahnfabrik, Bad Säckingen, Germany).

\section{Polishing}

The MZ samples were polished using a zirconia extraoral polishing kit (BruxZir Adjustment and Polishing Kit; Prismatik Dentalcraft Inc., Irvine, CA, USA) according to the manufacturer's instructions. The VE samples polished with the manufacturer's polishing kit (VITA ENAMIC Polishing Set Technical; VITAZahnfabrik). The IPS and LP samples were polished using a suitable polishing kit and instrument (K0293 IPS e.max Chairside Adjustment \& Polishing Kit; USA) at low rpm with light pressure.

\section{Two-body wear tests}

The wear tests were performed using a chewing simulator with six vertical and horizontal simulation chambers that allowed six samples to be tested simultaneously (Fig. 2). The antagonists in the wear test were 6-mm steatite balls (magnesium silicate; FOX Industries, Plochingen, USA), with one ball used for each sample. The tests were performed using a multifunctional chewing simulator (Dentarge; Analitik 
Medikal, Gaziantep, Turkey), with 240,000 chewing cycles of $49 \mathrm{~N}$ at $1.6 \mathrm{~Hz}$. Thermocycling was performed during simulation test, with 5000 thermal cycles at $5 / 55^{\circ} \mathrm{C}$.

The ceramic samples were scanned before and after testing using a laser abrasion measurement system (Laserscanner LAS-20; SD Mechatronik, Feldkirchen-Westerham, Germany; Fig. 3). The steatite antagonists were scanned with a CAD/CAM scanner (CEREC Omnicam; Dentsply Sirona, York, PA, USA; Fig. 4). To ensure the samples were maintained in a defined position for scanning, they were fixed with high viscosity silicon. The antagonist samples were subjected to scanning electron microscopy (S8AP0 with an EC3C Mount, 0.55x; Leica Microsystems, Heerbrugg, Switzerland) to provide additional qualitative data on the wear characteristics. Volume loss was calculated from the scanned images by using Geomagic Qualify three-dimensional software (3D Systems, Geomagic Qualify, USA) for the ceramic samples and Fusion 360 (Autodesk, San Rafael, CA, USA) for the antagonists.

\section{Statistical methods}

Analyses of this study performed using SPSS v24 statistical software (IBM Corp., Armonk, NY, USA). The Schapiro-Wilk test showed that the data were not normally distributed, so the non-parametric KruskalWallis test was used for the analyses. Differences between the groups were evaluated by the MannWhitney U-test with the Bonferroni correction (i.e., with the significance level calculated as [a / number of comparisons $]=[0.05 / 3]=0.016)$.

\section{Results}

\section{Antagonist volume loss analysis}

Table 2 summarizes the volume losses in the samples and antagonists for the four ceramic materials and the three finishes. Figures 5 and 6 illustrate the differences in volume losses between the ceramic materials.

With $\mathrm{MZ}$, the antagonist volume loss was significantly greater for the polished samples than for the glazed samples and controls $(p=0.011, p=0.004$, respectively), but there was no significant difference between the glazed and control samples. For VE, there were no significant differences in antagonist volume loss between the three finishes. For IPS, the antagonist volume loss was significantly higher for the control samples than for the glazed samples $(p=0.009)$. There were no significant differences between the control and polished samples or between the polished and glazed samples. For LP, the antagonist volume loss was significantly higher for the control samples than for the glazed and polished samples $(p=0.001$ and $p=0.0001$, respectively), but there was no significant difference between the polished and glazed samples.

\subsection{Ceramic sample volume loss analysis}


There were no statistically significant differences in sample volume loss between the three finishes (glazing, polishing, and control) for LP $(2=1.724, p=0.422)$, IPS $(2=3.915, p=0.141)$, or VE $(2=2.870, p$ $=0.238$ ). For $M Z$, the sample volume loss was significantly lower for the polished samples than for the control and glazed samples $(p=0.004$ and $p=0.0001$, respectively). However, there was no significant difference between control and glazed samples.

\section{Discussion}

Clinical wear patterns are complex and differ among patients. Testing a material's wear resistance requires analyses under different wear conditions [13]. In the present study, the wear behavior of dental ceramic with different surface treatments was investigated to establish the best treatment method for clinical use. In recent years, new aesthetic dental ceramic materials with excellent physical and mechanical properties have been produced for the restoration of tooth structure [13]. The wear characteristics of these restorative materials should closely match those of natural teeth to protect the opposing tooth and minimize occlusal disturbance $[15,16]$. Measurements of the wear volume loss of these materials can help with assessing their wear characteristics and can provide useful information about the longevity of the restoration and. $[16,17]$. In vitro studies cannot wholly replicate the human oral environment; however, they can create an environment in which to control and analyze the material's clinical efficiency. Previous studies have performed wear tests with a loading force of $49 \mathrm{~N}$ for 240,000 chewing cycles at a frequency of $1.6 \mathrm{~Hz}$ [18-20], which represents the average mastication loading. We used the same values in the present study in a computer-controlled chewing simulator, with 5000 thermal cycles at $5 / 55^{\circ} \mathrm{C}$. Sliding action produced by wear machines also plays an essential part in simulating intraoral wear. In the present study, the water used for the thermocycling served as an intermediate fluid to facilitate mechanical sliding under lubricated conditions.

Heintze et al. inspected three different methods to measure wear, using a three-dimensional (3D) laser system, a mechanical method, and an optical method to analyze both the volume and vertical loss of dental materials; they concluded that all three methods were suitable, but that the 3D laser method was faster and easier to use [16,21]. In the present study, the ceramic samples were scanned before and after the wear test with a laser abrasion measurement system. Processing the scanned data with 3D software allowed the scanned data points to be converted into the surface required for the analysis. The steatite antagonists were scanned using CAD/CAM and analyzed with different 3D software. Arsecularatne et al. reported several advantages of using the geometric method of macro-topographical examination and quantification [9], which is applicable to both flat and curved samples [13], and showed that the best method to achieve higher accuracy and specificity in the measurements is to use a 3D laser scanner [9]. Using a laser scanner can also eliminate errors and changes on the sample surface associated with the use of replicas, coating layers of the tested material to obtain optical measurements22-24].

The structure of the dental enamel differs among patients; indeed, the thickness and degree of mineralization can differ between teeth in the same oral cavity [25]. Morphological and structural variations in enamel complicate the standardization of wear examination [23]. Some studies have tried to 
achieve standard wear simulation using steatite antagonists with a diameter of $3 \mathrm{~mm}$ [26], whereas another study used 10-mm steatite antagonists [28]. Conversely, numerous studies have reported that steatite antagonists $6 \mathrm{~mm}$ in diameter were ideal for simulating human molars and that steatite material exhibited wear properties similar to those of composite materials and enamel [28-32]. Other studies have confirmed the suitability of steatite antagonists for in vitro wear testing [19]. Based on these findings, the present study used steatite balls with a diameter of $6 \mathrm{~mm}$ as the antagonists.

Surface hardness has been used as a measure of the wear value of dental restoration materials [33-35]. However, Hutchings et al. reported that there was no critical correlation between the hardness of the restoration material and the amount of wear of the antagonist and that wear behavior was associated more closely with the material microstructure, surface roughness, and environmental effects [15].

Polymer-infiltrated ceramic network material (PICN) imitates natural tooth properties more closely than other dental restorative materials [36], showing intermediate wear resistance compared to glass-ceramics [37]. However, a previous study showed that VE, a PICN, exhibited less material and antagonist wear than IPS e.max Press [38], as well as less antagonist wear than feldspathic ceramic [39]. Another study investigated the wear behavior of full crowns fabricated using CAD/CAM from nanoceramic composite, PICN, and lithium disilicate, and reported that PICN provided the most stable occlusion and that nanoceramic composite was the most antagonist-friendly [5]. In the present study, MZ showed higher wear resistance than IPS, LP, and the PICN VE. MZ showed the lowest antagonist wear, IPS and LP had a similar effect on antagonist wear, and the highest antagonist wear was observed with VE.

Thermocycling has a material-dependent effect on the wear mechanism, reducing the rate of wear in some materials, increasing it in others, and showing no effect on wear in some materials [19].

Thermocycling increased the roughness of most tested materials without affecting their hardness [40]. Wear has little influence on roughness and no influence on phase transformation [41]; however, glazing and/or polishing ceramic can influence the initial stage of the wear process [15]. Some studies have used polishing procedures applied to zirconia to increase the surface roughness, resulting in phase changes on the zirconia surface [38, 42]; conversely, other studies have reported that the polishing surface of zirconia resulted in less wear to the antagonist [43-46]. Verena et al. reported that polished or glazed MZ can provide an alternative to veneered dental restoration [47]. Beuer et al. used full-contour zirconia crowns for a period of six months [42]; the present study showed similar results when using flat samples for a one-year simulation. In this study, the tested ceramic restorations showed material wear loss that was comparable between the glazed and polished finishes. The exception to this was $M Z$, for which polishing resulted in less material wear than glazing. In addition, glazed IPS, LP, and VE, showed somewhat lower antagonist volume loss compared with polishing, although the differences were not statistically significant. In addition, polished MZ showed higher antagonist wear than glazed and control MZ.

This study demonstrated differences between materials through wear analysis and examining scan surface characteristics. However, these differences alone cannot completely determine the effects of the material properties under clinical conditions. Nevertheless, these in vitro studies have provided an 
indication of the potential clinical success of the materials tested. Several previous in vitro studies have evaluated the wear properties of dental ceramics [2,3,5,22,23], but further detailed evaluation of the materials for clinical use remains essential.

\section{Conclusion}

This study investigated how polishing and glazing affected the wear resistance of dental ceramics and the wear on the antagonist. The main findings were that MZ yielded superior wear behavior and lower antagonistic wear compared to the other tested ceramics, but that polishing MZ had adverse effects on the corresponding antagonist wear, whereas glazing resulted in the lowest antagonist wear. In addition, glazing resulted in lower antagonist volume loss (although not with statistical significance) than polishing for the IPS, LP, and VE ceramics.

\section{Declarations}

Ethics approval and consent to participate:

"Not applicable”

Consent for publication:

"Not applicable"

Availability of data and materials:

Competing interests:

"The authors declare that they have no competing interests"

Funding:

This research received no external funding.

Authors' contributions

Acknowledgements: The authors would like to thank B.Yaşa \& E.Çelik (İmir Katip Çelebi University, Faculty of Dentistry) for their help while using the simulator.

Authors' information (optional)

Mohammed Abujalala* andA.NehirÖzden

Department of Prosthodontics, Faculty of Dentistry, Near East University, Lefkosa, 99138 Mersin 10, Turkey * Correspondence: dr.moh.jalala@hotmail.com; Tel.: +90-392-680-2030 


\section{References}

1- Yamaguchi S, Kani R, Kawakami K, Tsuji M, Inoue S, Lee C, et al. Fatigue behavior and crack initiation of CAD/CAM resin composite molar crowns. Dent Mater. 2018;34:1578-1584.

2- D’Arcangelo C, Vanini L, Rondoni GD, Vadini M, De Angelis F. Wear evaluation of prosthetic materials opposing themselves. Oper Dent. 2018;43:38-50.

3- Heintze SD, Cavalleri A, Forjanic M, Zellweger G, Rousson V. Wear of ceramic and antagonist-A systematic evaluation of influencing factors in vitro. Dent Mater.2008;24:433-449.

4- Mello PC, Coppedê AR, Macedo AP, Mattos MDGCD, Rodrigues RCS, Ribeiro RF. Abrasion wear resistance of different artificial teeth opposed to metal and composite antagonists. J App Oral Sci. 2009;17:451-456.

5- Naumova E, Schneider S, Arnold W, Piwowarczyk A. Wear behavior of ceramic CAD/CAM crowns and natural antagonists. Mater. 2017;10:244.

6- Habib SR, Alotaibi A, Al Hazza N, Allam Y, AlGhazi M. Two-body wear behavior of human enamel versus monolithic zirconia, lithium disilicate, ceramometal and composite resin. J Adv Prosthodont. 2019;11:23-31.

7- Stawarczyk B, Frevert K, Ender A, Roos M, Sener B, Wimmer T. Comparison of four monolithic zirconia materials with conventional ones: Contrast ratio, grain size, four-point flexural strength and two-body wear. J Mech Behav Biomed Mater. 2016;59:128-138.

8- Mitov G, Heintze SD, Walz S, Woll K, Muecklich F, Pospiech P. Wear behavior of dental Y-TZP ceramic against natural enamel after different finishing procedures. Dent Mater. 2012;28:909-918.

9- Arsecularatne JA, Dingeldein JP, Hoffman M. An in vitro study of the wear mechanism of a leucite glass dental ceramic. Biosurface and Biotribology. 2015;1:50-61.

10- Ohashi K, Kameyama Y, Wada Y, Midono T, Miyake K, Kunzelmann KH, Nihei T. Evaluation and comparison of the characteristics of three pressable lithium disilicate glass ceramic materials.". Inter J Dev Res. 2017;7:16711-16716.

11- Bajraktarova-Valjakova E, Korunoska-Stevkovska V, Kapusevska B, Gigovski N, Bajraktarova-Misevska C, Grozdanov A. Contemporary Dental Ceramic Materials, A Review: Chemical Composition, Physical and Mechanical Properties, Indications for Use. Open Access Maced J Med Sci. 2018;6:1742.

12-Amer R, Kürklü D, Kateeb E, Seghi RR. Three-body wear potential of dental yttrium-stabilized zirconia ceramic after grinding, polishing, and glazing treatments. J. Prosthet. Dent. 2014;112:1151-1155. 
13- Yin R, Jang YS, Lee MH, Bae TS. Comparative Evaluation of Mechanical Properties and Wear Ability of Five CAD/CAM Dental Blocks. Mater. 2019;12:2252.

14- Stöckl C, Hampe R, Stawarczyk B, Haerst M, Roos M. Macro-and microtopographical examination and quantification of CAD-CAM composite resin 2-and 3-body wear. J Prosthet Dent. 2018;120:537-545.

15- Oh WS, DeLong R, Anusavice KJ. Factors affecting enamel and ceramic wear: a literature review. J Prosthet Dent. 2002;87:451-459.

16- Heintze SD, Cavalleri A, Forjanic M, Zellweger G, Rousson V. A comparison of three different methods for the quantification of the in vitro wear of dental materials. Dent Mater. 2006;22:1051-1062.

17- Kunzelmann KH, Jelen B, Mehl A, Hickel R. Wear evaluation of MZ100 compared to ceramic CAD/CAM materials. Int J Comp Dent. 2001;4:171-184.

18- Mörmann WH, Stawarczyk B, Ender A, Sener B, Attin T, Mehl A. Wear characteristics of current aesthetic dental restorative CAD/CAM materials: two-body wear, gloss retention, roughness and Martens hardness. J Mech Behave Biomed Mater. 2013;20:113-125.

19- Heintze SD. How to qualify and validate wear simulation devices and methods. Dent Mater. 2006;22:712-734.

20- Kim MJ, Oh SH, Kim JH, Ju SW, Seo DG, Jun SH, et al. Wear evaluation of the human enamel opposing different Y-TZP dental ceramics and other porcelains. J Dentist. 2012;40:979-988.

21- Choi JW, Song EJ, Shin JH, Jeong TS, Huh JB. In Vitro Investigation of Wear of CAD/CAM Polymeric Materials Against Primary Teeth. Mater. 2017; 10:1410.

22- Gwon B, Bae EB, Lee JJ, Cho WT, Bae HY, Choi JW, Huh JB. Wear Characteristics of Dental Ceramic CAD/CAM Materials Opposing Various Dental Composite Resins. Mater. 2019;12:1839.

23- Jung YS, Lee JW, Choi YJ, Ahn JS, Shin SW, Huh JB. A study on the in vitro wear of the natural tooth structure by opposing zirconia or dental porcelain. J Adv Prosthodont. 2010;2:111-115.

24- Tsujimoto A, Barkmeier WW, Fischer NG, Nojiri K, Nagura Y, Takamizawa T, Miazaki M. Wear of resin composites: Current insights into underlying mechanisms, evaluation methods and influential factors. Japan Dent Sci Rev. 2018;54:76-87.

25- D’Arcangelo C, Vanini L, Rondoni GD, Pirani M, Vadini M, Gattone M, De Angelis F. Wear properties of a novel resin composite compared to human enamel and other restorative materials. Oper Dent. 2014;39:612-618.

26- Preis V, Schmalzbauer M, Bougeard D, Schneider-Feyrer S, Rosentritt M. Surface properties of monolithic zirconia after dental adjustment treatments and in vitro wear simulation. J Dent. 
27- Preis V, Behr, M, Handel G, Schneider-Feyrer S, Hahnel S, Rosentritt M. Wear performance of dental ceramics after grinding and polishing treatments. J Mech BehaveBiomed Mater. 2012;10:13-22.

28- D'Arcangelo C, Vanini L, Rondoni GD, De Angels F. Wear properties of dental ceramics and porcelains compared with human enamel. J Prosthet Dent. 2016;115:350-355.

29-Stawarczyk B, Özcan M, Schmutz F, Trottmann A, Roos M, Hämmerle CH. Two-body wear of monolithic, veneered and glazed zirconia and their corresponding enamel antagonists. Acta Odontol Scand. 2013;71:102-112.

30- Kewekordes T, Wille S, Kern M. Wear of polyetherketoneketones-Influence of titanium dioxide content and antagonistic material. Dent Mater. 2018;34:560-567.

31- Hu X, Zhang Q, Ning J, Wu W, Li C. Study of Two-Body Wear Performance of Dental Materials. J Nation Med Assoc. 2018;110:250-255.

32- Wassell RW, McCabe JE, Walls AWG. A two-body frictional wear test. J Dent Res. 1994;73:1546-1553.

33- Chun KJ, Lee JY. Comparative study of mechanical properties of dental restorative materials and dental hard tissues in compressive loads. J Dent biome. 2014;5.

34- Monasky GE, Taylor DF. Studies on the wear of porcelain, enamel, and gold. J Prosthet Dent. 1971;25:299-306.

35- Fisher RM, Moore BK, Swartz ML, Dykema RW. The effects of enamel wear on the metal-porcelain interface. J Prosthet Dent. 1983;50:627-31.

36- Coldea A, Swain MV, Thiel N. Mechanical properties of polymer-infiltrated-ceramic-network materials. Dent Mater. 2013;29:419-426.

37- Hao Z, Ma Y, Liu W, Meng Y, Nakamura K, Shen, J. Wang H. Influence of low-temperature degradation on the wear characteristics of zirconia against polymer-infiltrated ceramic-network material. J Prosthet Dent. 2018;120:596-602.

38- Elhomiamy E. Wear Behaviour and Surface Roughness of Polymer Infiltrated Ceramic Material Compared to Pressable Glass Ceramic. Alexandria Dent J.2015;40.

39- Ashtiani AH, Azizian M, Rohani A. Comparison the degree of enamel wear behavior opposed to Polymer-infiltrated ceramic and feldspathic porcelain. Dent Res J.2019; 16:71.

40- Oliveira JCD, Aiello G, Mendes B, Urban VM, Campanha NH, Jorge JH. Effect of storage in water and thermocycling on hardness and roughness of resin materials for temporary restorations. Mater Res. 2010;13:355-359. 
41-Beuer F, Stimmelmayr M, Gueth JF, Edelhoff D, Naumann M. In vitro performance of full-contour zirconia single crowns. Dent Mater. 2012;28:449-456.

42- Bartolo D, Cassar G, Husain NAH, Özcan M, Camilleri J. Effect of polishing procedures and hydrothermal aging on wear characteristics and phase transformation of zirconium dioxide. J Prosthet Dent. 2017,117:545-551.

43- Pelka M, Ebert J, Schneider H, Kramer N, Petschelt A. Comparison of two-and three-body wear of glass-ionomers and composites. Eur J oral Sci. 1996;104:132-137.

44- Li H, Zhou ZR. Wear behaviour of human teeth in dry and artificial saliva conditions. Wear. 2001;249:980-984.

45- Seghi RR., Rosenstiel SF, Bauer P. Abrasion of human enamel by different dental ceramics in vitro. J Dent Res.1991;70:221-225.

46- Kisi EH, Howard C J. Crystal structures of zirconia phases and their inter-relation. In KeyEng Mater. 1998;53:1-36.

47- Preis V, Behr M, Hahnel S, Handel G, Rosentritt M. In vitro failure and fracture resistance of veneered and full-contour zirconia restorations. J Dent. 2012;40:921-928.

\section{Tables}

Table 1: The four ceramic materials used in the study

\begin{tabular}{|c|c|c|}
\hline Material & Filler composition & Description \\
\hline $\begin{array}{l}\text { Monolithic } \\
\text { zirconia }\end{array}$ & $\begin{array}{l}\mathrm{SiO}_{2}(40 \mathrm{~nm}), \mathrm{Al}_{2} \mathrm{O}_{3}(20 \\
\mathrm{nm})\end{array}$ & $\begin{array}{l}\text { CopraSupreme } 98 \times 14 \text { mm S Zr blank HT-S 1100 MPa; } \\
\text { Whitepeaks Dental Solutions, Hamminkeln, Germany }\end{array}$ \\
\hline $\begin{array}{l}\text { IPS e.max } \\
\text { CAD }\end{array}$ & $\begin{array}{l}\text { Leucite-reinforced glass- } \\
\text { ceramic of } \mathrm{SiO}_{2}-\mathrm{Al}_{2}-\mathrm{O}_{3}-\mathrm{K}_{2} \mathrm{O} \text {. }\end{array}$ & HT A2 /C14; Ivoclar Vivadent, Schaan, Liechtenstein \\
\hline $\begin{array}{c}\text { Vita } \\
\text { Enamic }\end{array}$ & $\begin{array}{l}\text { Feldspar ceramic enriched } \\
\text { with aluminum oxide }\end{array}$ & $\begin{array}{l}\text { 2M1-HT EM-14; VITA-Zahnfabrik, Bad Säckingen, } \\
\text { Germany }\end{array}$ \\
\hline $\begin{array}{l}\text { GC Initial } \\
\text { Li Si Press }\end{array}$ & $\begin{array}{l}\text { High-strength lithium } \\
\text { disilicate glass-ceramic }\end{array}$ & $\begin{array}{l}\text { HT-A2 lithium disilicate glass ceramics ingot, } 3 \mathrm{~g} \times 5 \text { pieces; } \\
\text { GC Corporation, Tokyo, Japan }\end{array}$ \\
\hline
\end{tabular}

Table 2. Results of the wear testing for the samples and antagonists with glazing, polishing, or neither (control) surface treatment 


\begin{tabular}{|c|c|c|c|c|c|c|c|}
\hline \multicolumn{2}{|c|}{ Material } & \multicolumn{3}{|c|}{$\begin{array}{l}\text { Antagonist volume loss } \\
\qquad\left(\mathrm{mm}^{3}\right)\end{array}$} & \multicolumn{3}{|c|}{$\begin{array}{l}\text { Sample volume loss } \\
\qquad\left(\mathrm{mm}^{3}\right)\end{array}$} \\
\hline & & Glaze & Control & Polish & Glaze & Control & Polish \\
\hline \multirow{5}{*}{ MZ } & Median & $0.0240^{\mathrm{C}}$ & $0.0160^{\mathrm{C}}$ & $0.0365 \mathrm{AB}$ & $0.0305^{c}$ & $0.0275^{\mathrm{c}}$ & $0.0200 \mathrm{ab}$ \\
\hline & (Range) & (0.012- & (0.011- & $(0.022-$ & $(0.022-$ & $(0.020-$ & (0.013- \\
\hline & & 0.029) & 0.071) & 0.052) & 0.035) & 0.032) & 0.026) \\
\hline & (Q3 - & 0.0045 & 0.0100 & 0.0282 & 0.0075 & 0.0085 & 0.0720 \\
\hline & Q1) & & & & & & \\
\hline \multirow{5}{*}{ VE } & Median & 0.0910 & 0.0952 & 0.0910 & 0.2500 & 0.2350 & 0.2000 \\
\hline & (Range) & (0.087- & (0.085- & (0.071- & (0.110- & (0.120- & (0.170- \\
\hline & & 0.098) & $0.121)$ & 0.095) & $0.380)$ & $0.330)$ & $0.260)$ \\
\hline & (Q3 - & 0.0048 & 0.0155 & 0.0045 & 0.1575 & 0.1200 & 0.0450 \\
\hline & Q1) & & & & & & \\
\hline \multirow{5}{*}{ LP } & Median & $0.0785^{\mathrm{B}}$ & $0.0880 \mathrm{AC}$ & $0.0777^{\mathrm{B}}$ & 0.1750 & 0.2100 & 0.1950 \\
\hline & (Range) & (0.069- & (0.081- & (0.074- & (0.120- & (0.120- & (0.080- \\
\hline & & 0.086) & $0.094)$ & 0.082) & $0.250)$ & $0.250)$ & $0.290)$ \\
\hline & (Q3 - & 0.0118 & 0.0095 & 0.0060 & 0.0875 & 0.0625 & 0.1750 \\
\hline & Q1) & & & & & & \\
\hline \multirow[t]{5}{*}{ IPS } & Median & $0.0765^{\mathrm{B}}$ & $0.0845^{\mathrm{A}}$ & 0.0830 & 0.1150 & 0.1400 & 0.1400 \\
\hline & (Range) & (0.026- & $(0.076-$ & (0.070- & (0.040- & $(0.090-$ & (0.090- \\
\hline & & $0.085)$ & $0.095)$ & 0.095) & $0.180)$ & $0.190)$ & $0.190)$ \\
\hline & (Q3 - & 0.0103 & 0.0102 & 0.0120 & 0.1125 & 0.0550 & 0.0550 \\
\hline & Q1) & & & & & & \\
\hline
\end{tabular}

Superscript letters within a row: A, significant difference from the antagonist glaze group; B, significant difference from the antagonist control group; C, significant difference from the antagonist glaze group; a, significant difference from the glazed samples; b, significant difference from the control samples; c, significant difference from the polished samples $(\mathrm{p}<0.05)$. Abbreviations: $\mathrm{MZ}$, monolithic zirconia; VE, VITA Enamic; LP, GC Initial LiSi Press; IPS, IPS e.max CAD; Q3 - Q1, difference between quartile 3 and quartile 1.

\section{Figures}



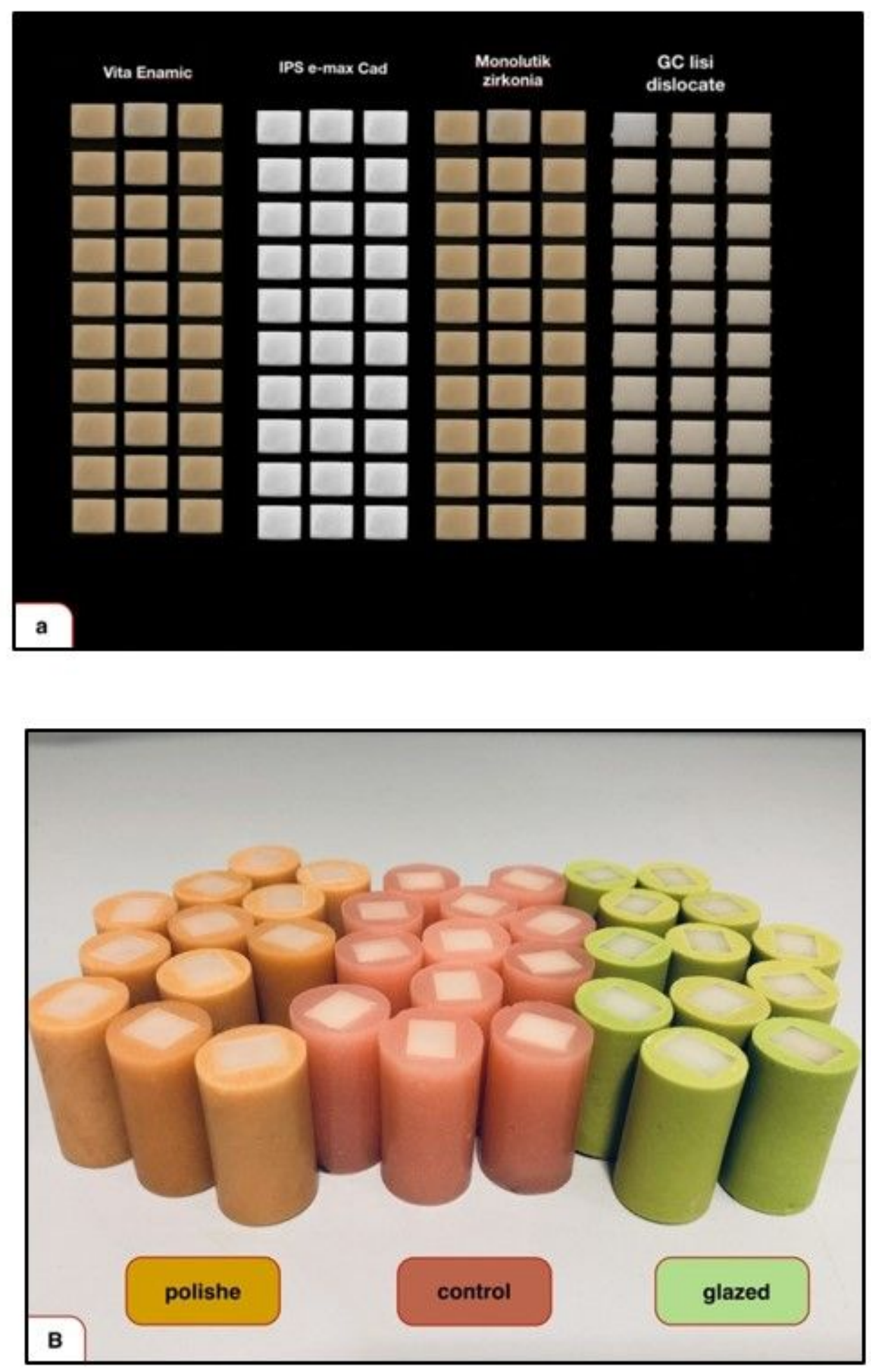

\section{Figure 1}

The samples before testing. (a) Ceramic samples after cutting to the required size and shape. (b) The ceramic samples mounted on resin blocks of different colors according the surface treatment. 

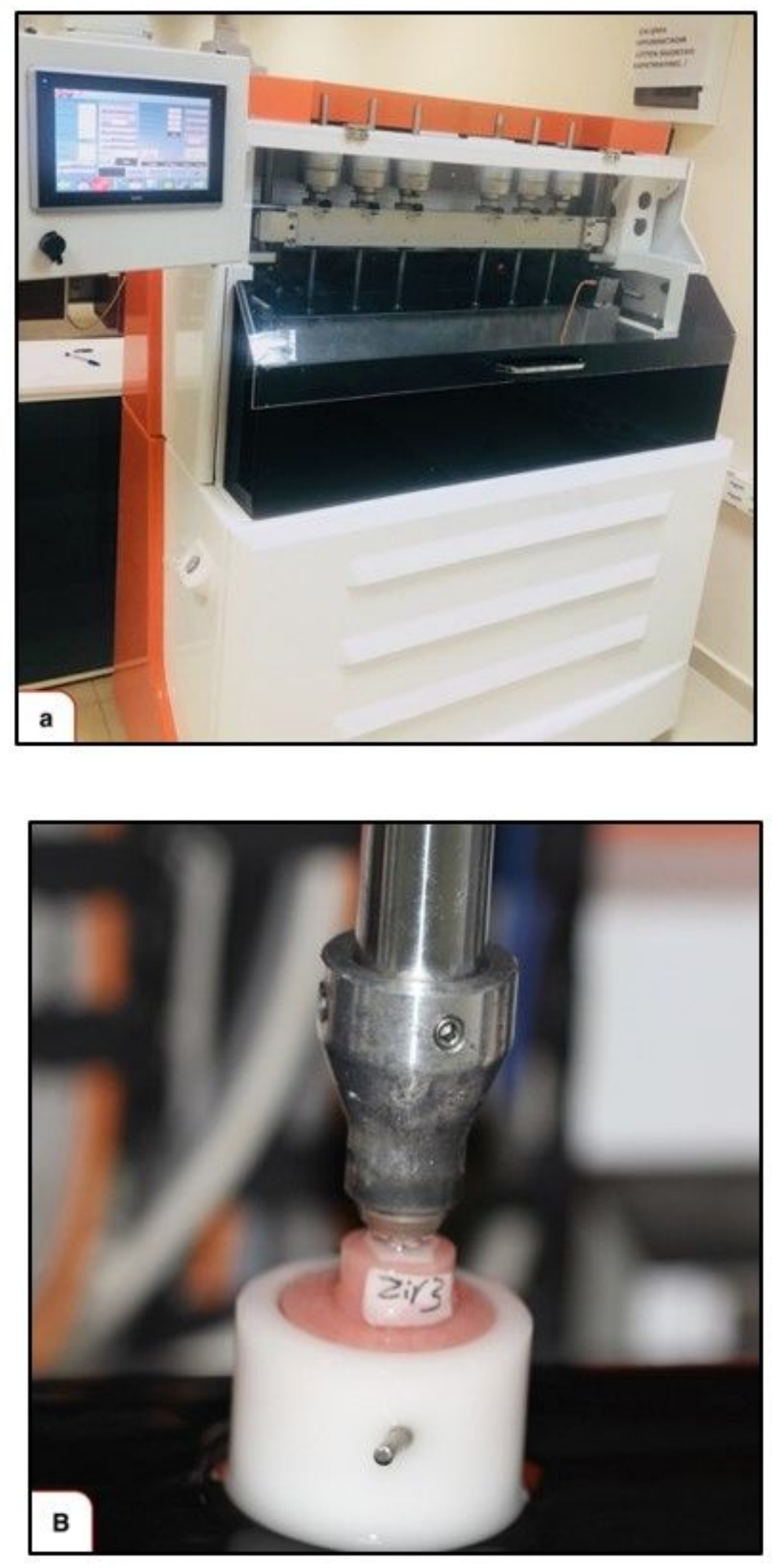

Figure 2

The chewing simulation. (a) One batch of six samples in the chewing simulator. (b) A ceramic sample mounted on a resin block undergoing the chewing simulation, with a steatite ball antagonist in a holder above it. 

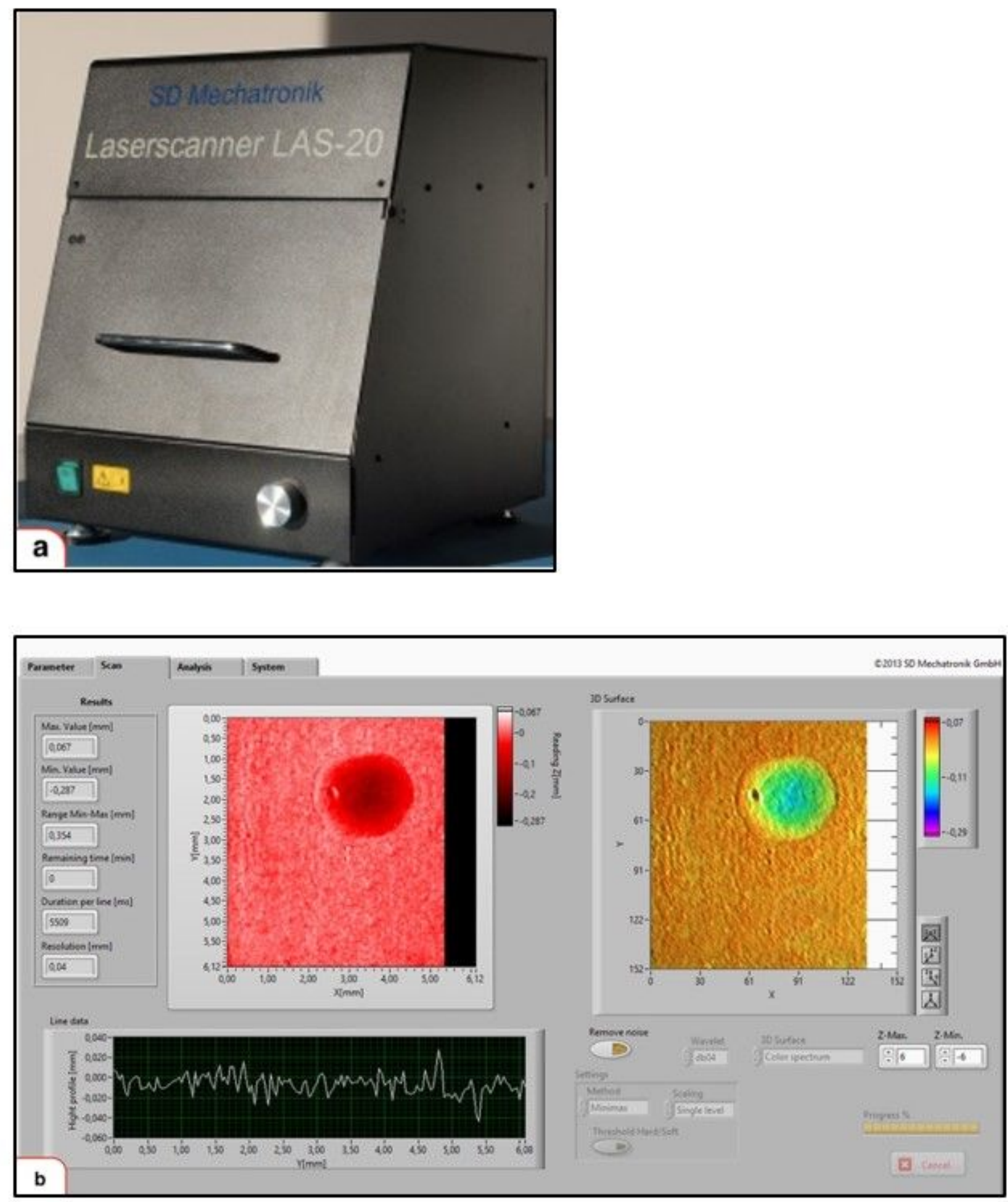

\section{Figure 3}

Measuring volume loss in the ceramic samples. (a) The laser abrasion measurement system (Laserscanner LAS-20). (b) An example of a sample volume loss after scanning. 


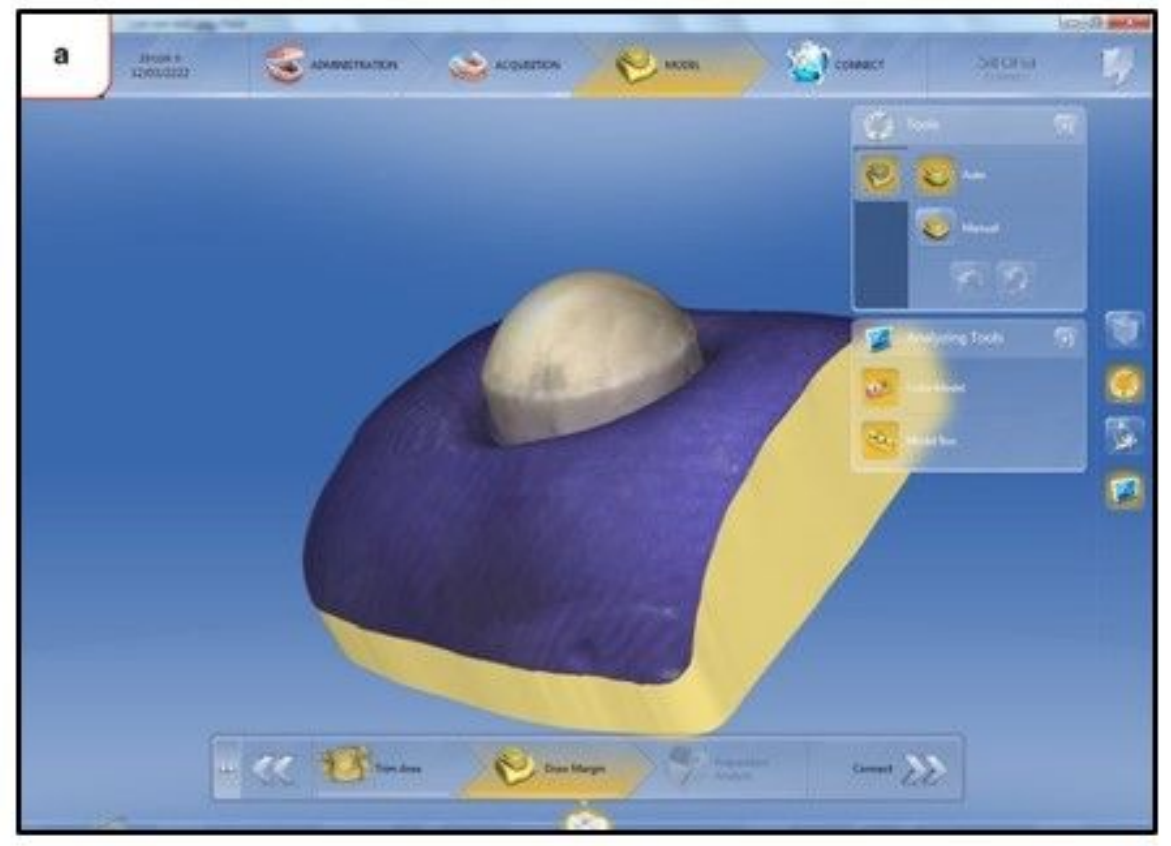

\section{b}

Figure 4

Measuring volume loss in the steatite antagonists. (a) Each antagonist was scanned with a CAD/CAM scanner (CEREC Omnicam). (b) After scanning, the volume loss was calculated using Geomagic Control $X$ software. The image shows an STL file of an antagonist after the wear test. 

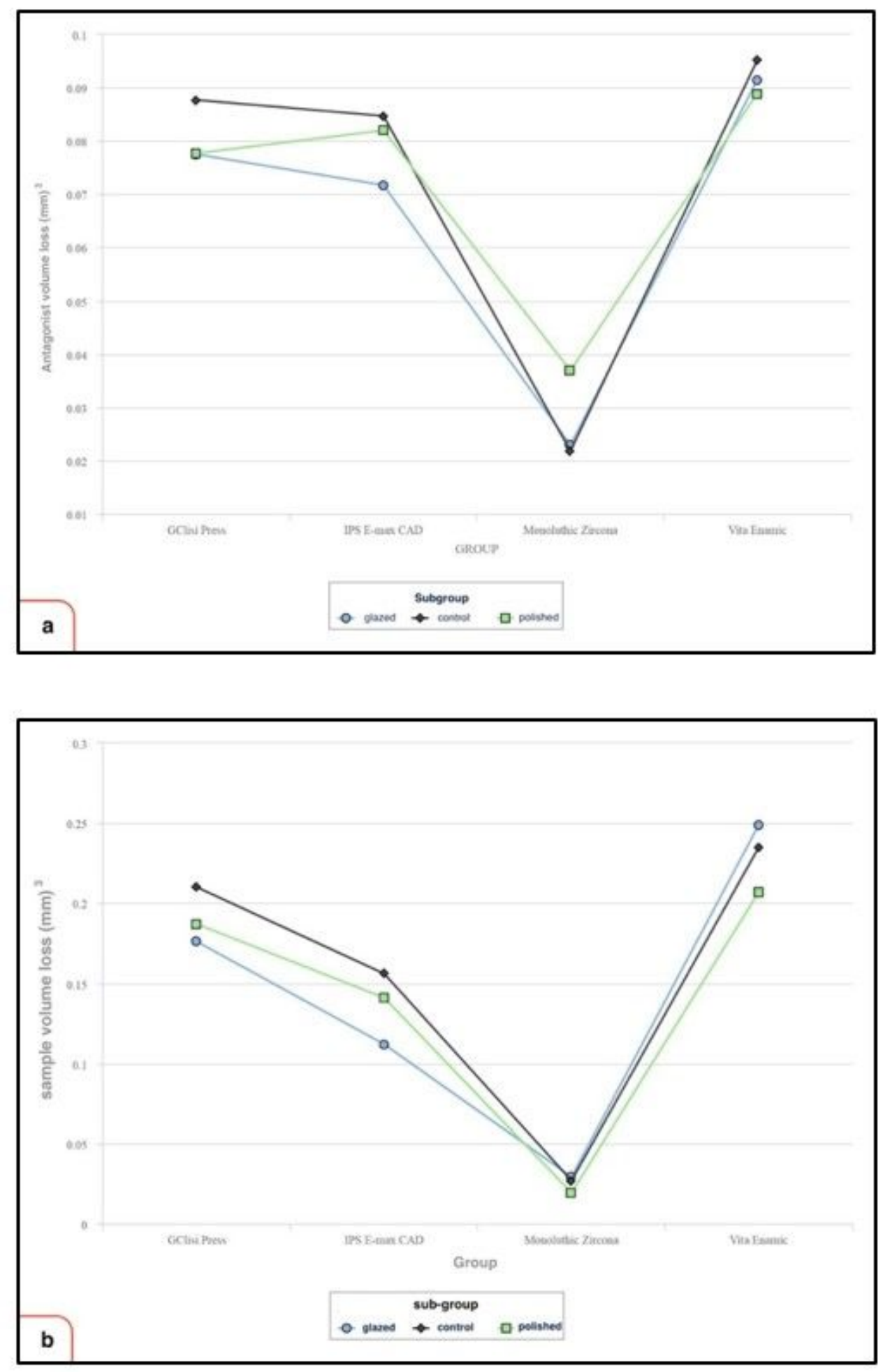

Figure 5

Results of the volume loss analyses for the three finishes (polishing, glazing, and control). (A) Antagonists. (B) Ceramic materials. 

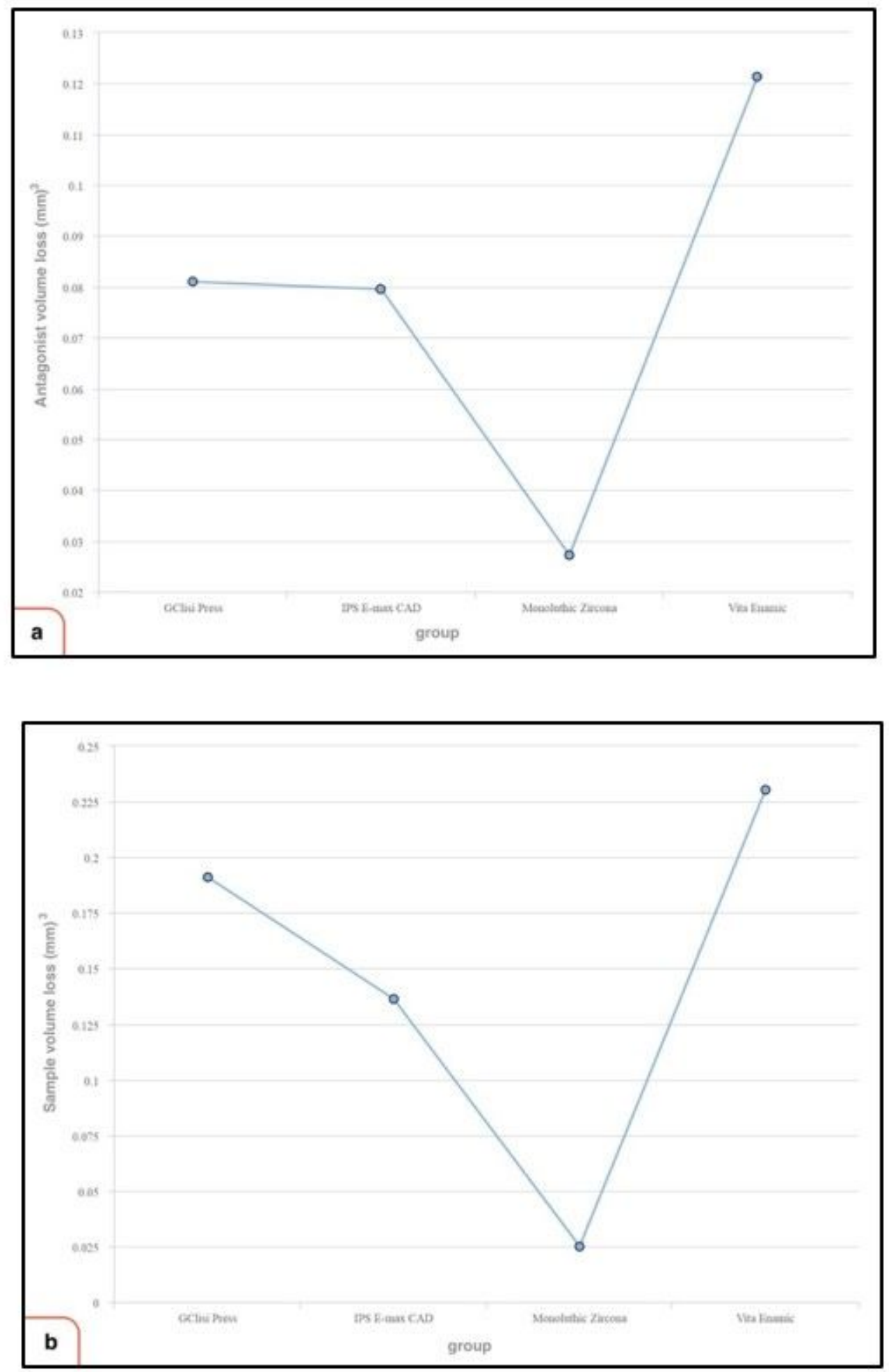

Figure 6

Volume loss for the antagonists (A) and ceramic materials (B) during the wear simulation. 